\title{
Association between elevated blood glucose level and non-valvular atrial fibrillation: a report from the Guangzhou heart study
}

\author{
Lu Fu ${ }^{1,2+}$, Hai Deng ${ }^{1,2+}$, Wei-dong Lin ${ }^{1,2}$, Shang-fei He ${ }^{1,2}$, Fang-zhou Liu ${ }^{1,2}$, Yang Liu ${ }^{1,2}$, Xian-zhang Zhan ${ }^{1,2}$, \\ Xian-hong Fang ${ }^{1,2}$, Hong-tao Liao ${ }^{1,2}$, Wei Wei ${ }^{1,2}$, Zi-li Liao ${ }^{1,2}$, Li-hong Tang ${ }^{1,2}$, Zu-yi Fu ${ }^{1,2}$, Mu-rui Zheng ${ }^{3}$, \\ Shu-lin $\mathrm{Wu}^{1,2}$ and Yu-mei Xue ${ }^{1,2^{*}}$
}

\begin{abstract}
Background: To estimate the prevalence of elevated blood glucose level (EBG, including type 2 diabetes mellitus and impaired fasting glucose), and its association with non-valvular atrial fibrillation (NVAF) in Guangzhou, China.

Methods: The population-based follow-up Guangzhou Heart Study collected baseline data from July 2015 to August 2017 among 12,013 permanent residents aged $\geq 35$ from 4 Guangzhou districts. Two streets (Dadong and Baiyun) in the Yuexiu District, and one street (Xiaoguwei) and two towns (Xinzao and Nancun) in the Panyu District were chosen as representative of urban and rural areas, respectively. Each participant completed a comprehensive questionnaire, and underwent physical examination, blood sample collection for laboratory testing, electrocardiography, and other evaluations. Multivariable logistic regression analyses were used to estimate the independent association between hyperglycemia and NVAF prevalence.
\end{abstract}

Results: The prevalence of EBG in overall study population was 29.9\%. Compared with residents without EBG, the odds ratio (OR) for AF among residents with EBG was significantly higher (1.94, 95\% confidence interval [CI]: 1.40$2.70, P<0.001)$, even after multivariate adjustment for metabolic abnormalities ( $\mathrm{OR}=1.60,95 \% \mathrm{Cl}: 1.14-2.25, P=$ $0.007)$, and driven by women ( $\mathrm{OR}=1.80,95 \% \mathrm{Cl}: 1.12-2.91, P=0.016)$.

Conclusions: In Guangzhou, China, prevalence of EBG is high among residents aged $\geq 35$ years and associated with a multivariate adjusted increase in prevalence of NVAF overall and in women.

Keywords: Hyperglycemia, Type 2 diabetes mellitus, Impaired fasting glucose, Non-valvular atrial fibrillation, Sex

\section{Background}

Atrial fibrillation (AF), one of the most common cardiac arrhythmias in the general population, is associated with increased risk of ischemic stroke/systemic embolism, heart failure, myocardial infarction and mortality from

\footnotetext{
* Correspondence: xymgdci@163.com

† Lu Fu and Hai Deng contributed equally to this work.

'Department of Cardiology, Guangdong Provincial People's Hospital, Guangdong Academy of Medical Sciences, Guangdong Cardiovascular Institute, Guangzhou 510080, China

${ }^{2}$ Guangdong Provincial Key Laboratory of Clinical Pharmacology, Research Center of Medical Sciences, Guangdong Academy of Medical Sciences, Guangzhou 510080, China

Full list of author information is available at the end of the article
}

cardiovascular disease [1-3]. Advancing age, type 2 diabetes mellitus (T2D), hypertension, obesity, and myocardial infarction are the major risk factors for the development of AF [4-6]; male, smoking, alcohol intake, dyslipidemia also are risk factors for AF [7].

Abnormal glucose metabolism, characterized by elevated blood glucose level (EBG), is one of the most common metabolic diseases, and mainly includes T2D and pre-diabetes status, i.e., impaired fasting glucose (IFG). Individuals with T2D (summary relative risk $=1.34,95 \%$ CI: $1.07-1.68$ ) [8] or IFG (hazard ratio $=1.16, P=0.017$ ) [9] have a significantly increased risk for new-onset AF.

(C) The Author(s). 2019 Open Access This article is distributed under the terms of the Creative Commons Attribution 4.0 International License (http://creativecommons.org/licenses/by/4.0/), which permits unrestricted use, distribution, and 
The prevalence of diabetes in both rural and urban communities of China is increasing rapidly [10]. The extensive overlap between the risk factors for EBG and those for AF, such as obesity, hypertension, and other metabolic diseases [11], may underlie the observed association between EBG and AF [12-14], warranting adequate adjustment for confounders in its evaluation, which is the aim of the present population-based sampling study of the permanent residents in Guangzhou city conducted by The Guangdong Institute of Cardiovascular Disease and approved by the Guangzhou Medical Ethics Committee of the Chinese Medical Association.

\section{Methods}

\section{Study population}

The collection of baseline data in the Guangzhou Heart Study, a population-based follow-up study, began in July 2015 and completed in August 2017 in Guangzhou. Dadong and Baiyun streets from the Yuexiu District were randomly selected to represent the urban areas while Xiaoguwei street, and the towns of Xinzao and Nancun from the Panyu District the rural ones. Permanent residents aged 35 and older from the randomly chosen locations in Guangzhou city were recruited into this study during 3 mobilization rounds of door-to-door visits or telephone contacts and using a randomized multistage cluster sampling. Study details were informed to study participants and written informed consent allowing access to their medical tests and records was provided in advance of enrollment.

Study inclusion criteria were: 1) Guangzhou permanent residents registered in the Guangzhou Household Register; 2) age $\geq 35$ years old; and 3 ) living in the randomly chosen communities for at least 6 months from the day that they enrolled in the survey. Individuals with the following conditions were excluded: 1) mobility difficulties including high paraplegia; 2) mental or cognitive disorders including disturbance of understanding, dementia, and deaf-mutters; 3) pregnant or lactating females; 4) malignant tumors under treatment; 5) floating population including tenants; 6) Guangzhou residents not living in the selected communities for at least 6 months by the day they participated in the survey; 7) non-Guangzhou residents; and 8) non-responders during the 3-round mobilization.

\section{Data collection and measurement}

The trained field researchers, who had received systematic training for questionnaire, physical measurements, and quality control to guarantee standardization of the investigation procedure, conducted a face-to-face interview with the participant who submitted the signed consent described by Deng et al. [15]. A standard questionnaire was used to obtain each participant's demographic information and relevant data for AF at the baseline survey, including: 1) general demographic and socioeconomic characteristics (including age and sex); 2) personal history of disease (including hypertension, T2D, valvular disease, hyperthyroidism, chronic obstructive pulmonary disease (COPD), hyperuricemia (HUA), and chronic kidney disease (CKD); 3) lifestyle habits (including smoking and alcohol consumption); and 4) methodological details were as reported by Deng et al. [15].

Physical measurements including height, weight, waist circumference and blood pressure (BP) were performed using standard instruments and protocols. Participants took a sitting position for $5 \mathrm{~min}$ before the measurement of BP. Used the electronic blood pressure monitor to lay flat on the table, zero, and placed the center of the cuff in line with the heart of the subject. The lower edge of the cuff was $2-3 \mathrm{~cm}$ higher than the elbow joint, and the cuff was firmly tied. All the measurements were recorded twice and the mean of the two values was used for analysis.

The fasting blood sampling were arranged in the morning, and the residents were asked to have an empty stomach and a sitting position. Coagulant tubes with blood samples were centrifuged as soon as possible after blood collection at site before transport. Blood samples were stored in a refrigerator at $-20^{\circ} \mathrm{C}$, and transported to a third-party testing institution according to standardized procedures for the testing of relevant blood indicators, such as fasting plasma glucose (FPG), lipid profile, and renal function assessment, among others in $6 \mathrm{~h}$. The FPG was measured by the hexokinase method.

Experienced professionals from The Guangdong Cardiovascular Institute conducted additional evaluations including electrocardiography (ECG) and 24-h single lead ECG monitoring. Each electrocardiogram was performed by well-trained physician and diagnosed by two specifc electrophysiological experts.

\section{Definitions}

AF was diagnosed based on ECG findings (i.e., absence of consistent $P$ waves, presence of rapid, irregular $f$ waves with a frequency of 350-600 beats/min, and an irregular ventricular response) and/or a history of physician-confirmed AF $[16,17]$. All residents with AF underwent cardiac ultrasonography to assess for valvular AF. NVAF was diagnosed as per guidelines [18].

T2D was defined as a FPG level $\geq 7.0 \mathrm{mmol} / \mathrm{L}$ or a history of physician-confirmed T2D; and IFG was defined as a FPG level of $5.6-6.9 \mathrm{mmol} / \mathrm{L}$ in the absence of a previous diagnosis of diabetes per ADA criteria [19]. Participants with T2D or IFG were assigned to the EBG group and the rest to the normal control group. 
Metabolic diseases (MetS) was defined as the presence of three or more of the following risk factors: elevated waist circumference (diagnosed as a waist circumference $\geq 90 \mathrm{~cm}$ for males and $\geq 80 \mathrm{~cm}$ for females); elevated triglycerides (TG) level: $>150 \mathrm{mg} / \mathrm{dL}(1.7 \mathrm{mmol} / \mathrm{L})$, or drug treatment for elevated TG; reduced high-density lipoprotein (HDL) cholesterol: $<40 \mathrm{mg} / \mathrm{dL}(1.00 \mathrm{mmol} /$ $\mathrm{L})$ in men and $<50 \mathrm{mg} / \mathrm{dL}(1.30 \mathrm{mmol} / \mathrm{L})$ in women, or drug treatment for reduced HDL; elevated BP (diagnosed as a systolic blood pressure (SBP) $\geq 130 \mathrm{mmHg}$ and/or diastolic blood pressure (DBP) $\geq 85 \mathrm{mmHg}$ and/or antihypertention drug treatment in a patient with a history of physician-confirmed hypertension); and elevated FPG: FPG $>5.6 \mathrm{mmol} / \mathrm{L}(100 \mathrm{mg} / \mathrm{dL})$, or previously diagnosed T2D [20]. Hyperuricemia (HUA) was defined as a uric acid level $>420 \mu \mathrm{mol} / \mathrm{L}(7 \mathrm{mg} / \mathrm{dL})$ for males and $>$ $360 \mu \mathrm{mol} / \mathrm{L}(6 \mathrm{mg} / \mathrm{dL})$ for females. eGFR was calculated by the CKD-EPI formula [21]. Chronic kidney disease

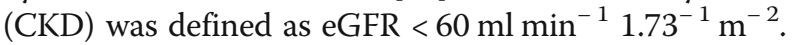

\section{Statistical analysis}

All statistical analyses were conducted with SPSS 22.0 statistical software (SPSS, Inc., Chicago, IL, USA). Differences between groups were assessed using Student's Ttest for continuous variables and $\chi^{2}$ test for categorical variables. Univariable logistic regression analysis and multivariable logistic regression analysis were performed to estimate the association between EBG and the prevalence of NVAF. Factorial analysis was used to test interaction effects between age and sex on the prevalence of EBG, and that between sex and EBG on the prevalence of AF. Data are presented as odds ratio (OR) and 95\% confidence interval (CI), mean \pm standard deviation (SD), or frequency and percentages. All statistical tests were 2sided, and a $P<0.05$ was considered statistically significant.

\section{Results}

\section{Characteristics of the study population}

A total of 12,013 residents were enrolled, and 11,634 completed the entire data collection. After excluding 145 individuals with valvular disease, the final study population was comprised of 4047 men and 7441 women with a mean age of $58.2 \mathrm{y}$. AF was diagnosed in 175 residents: 57 by previous or field ECG, 81 by portable single lead ECG, and 37 by both. The overall prevalence of $\mathrm{AF}$ was $1.46 \%$. Among the 175 participants, 31 were diagnosed with valvular disease, therefore, the remaining 144 NVAF were entered into the final data analysis.

The proportion of EBG was $29.9 \%$ in the overall population $(31.9 \%$ in men and $28.9 \%$ in women). Individuals with EBG were older, more often men $(P=0.001)$, and more often came from urban, with higher weight, body mass index (BMI), waist circumference, SBP and DBP, and levels of FPG, cholesterol (CHOL), TG, creatinine, low-density lipoprotein cholesterol (LDL), and higher proportions of elevated waist circumference, tea consumption, history of hypertension, HUA, and CKD than the no EBG group (all remaining $P<0.001$ ). Participants with EBG also had significantly lower HDL levels $(P<$ 0.001). There were no significant differences in height, smoking or alcohol consumption status, or history of

Table 1 Characteristics of the Study Population

\begin{tabular}{|c|c|c|c|}
\hline Characteristics & $\begin{array}{l}\text { EBG } \\
(n=3440)\end{array}$ & $\begin{array}{l}\text { No EBG } \\
(n=8048)\end{array}$ & $P$-value \\
\hline Men (\%) & 37.6 & 34.2 & 0.001 \\
\hline Age (years) & $62.6 \pm 10.5$ & $56.4 \pm 11.8$ & $<0.001$ \\
\hline Height (cm) & $158.3 \pm 8.3$ & $158.6 \pm 8.2$ & 0.079 \\
\hline Weight (kg) & $62.7 \pm 11.1$ & $59.5 \pm 10.5$ & $<0.001$ \\
\hline $\mathrm{BMI}\left(\mathrm{kg} \mathrm{cm}^{-2}\right)$ & $25.0 \pm 3.6$ & $23.6 \pm 3.4$ & $<0.001$ \\
\hline Waist circumference $(\mathrm{cm})$ & $87.9 \pm 9.9$ & $82.9 \pm 9.8$ & $<0.001$ \\
\hline Urban $(n, \%)$ & $1900,55.2$ & $3503,43.5$ & $<0.001$ \\
\hline $\mathrm{SBP}(\mathrm{mmHg})$ & $137.8 \pm 20.6$ & $127.4 \pm 19.7$ & $<0.001$ \\
\hline $\mathrm{DBP}(\mathrm{mmHg})$ & $82.7 \pm 11.7$ & $79.8 \pm 11.5$ & $<0.001$ \\
\hline $\mathrm{TG}\left(\mathrm{mmol} \mathrm{I}^{-1}\right)$ & $2.1 \pm 1.9$ & $1.5 \pm 1.2$ & $<0.001$ \\
\hline $\mathrm{HDL}\left(\mathrm{mmol} \mathrm{I}^{-1}\right)$ & $1.4 \pm 0.4$ & $1.6 \pm 0.4$ & $<0.001$ \\
\hline $\mathrm{CHOL}\left(\mathrm{mmol}{ }^{-1}\right)$ & $5.6 \pm 1.2$ & $5.4 \pm 1.1$ & $<0.001$ \\
\hline $\mathrm{LDL}\left(\mathrm{mmol} \mathrm{I}^{-1}\right)$ & $3.7 \pm 1.1$ & $3.6 \pm 1.0$ & $<0.001$ \\
\hline $\mathrm{FPG}\left(\mathrm{mmol} \mathrm{I}^{-1}\right)$ & $7.0 \pm 2.2$ & $5.0 \pm 0.4$ & $<0.001$ \\
\hline Elevated waist circumference (\%) & 67.5 & 48.0 & $<0.001$ \\
\hline Elevated TG (\%) & 45.4 & 28.2 & $<0.001$ \\
\hline Reduced HDL (\%) & 12.0 & 7.1 & $<0.001$ \\
\hline Elevated BP (\%) & 76.8 & 53.1 & $<0.001$ \\
\hline Non-valvular AF $(n, \%)$ & $65,1.9$ & $79,1.0$ & $<0.001$ \\
\hline Hyperthyroidism (n, \%) & $170,5.0$ & $373,4.6$ & 0.473 \\
\hline $\operatorname{COPD}(n, \%)$ & $203,6.0$ & $435,5.4$ & 0.286 \\
\hline Hypertension (n, \%) & $1588,46.2$ & $1789,22.2$ & $<0.001$ \\
\hline HUA $(n, \%)$ & $1675,48.7$ & $2875,35.7$ & $<0.001$ \\
\hline CKD $(n, \%)$ & $514,14.9$ & $736,9.1$ & $<0.001$ \\
\hline Smoking $(n, \%)$ & $763,22.2$ & $1704,21.2$ & 0.234 \\
\hline Alcohol consumption $(n, \%)$ & $719,20.9$ & $1732,21.5$ & 0.471 \\
\hline Tea consumption $(n, \%)$ & $2607,75.8$ & $5785,71.9$ & $<0.001$ \\
\hline
\end{tabular}

Data are presented as mean \pm SD or $n(\%)$. Elevated waist circumference was diagnosed as a waist circumference $>90 \mathrm{~cm}$ for males and $>80 \mathrm{~cm}$ for females. Elevated TG was diagnosed as a TG level $>150 \mathrm{mg} / \mathrm{dL}(1.7 \mathrm{mmol} / \mathrm{L})$, or drug treatment for elevated TG. Reduced HDL was diagnosed as a HDL level $<40$ $\mathrm{mg} / \mathrm{dL}(1.00 \mathrm{mmol} / \mathrm{L})$ in $\mathrm{men}$ and $<50 \mathrm{mg} / \mathrm{dL}(1.30 \mathrm{mmol} / \mathrm{L})$ in women, or drug treatment for reduced $\mathrm{HDL}$. Elevated $\mathrm{BP}$ was diagnosed as a $\mathrm{SBP} \geq 130 \mathrm{mmHg}$ and/or DBP $\geq 85 \mathrm{mmHg}$ and/or antihypertention drug treatment in a patient with a history of physician-confirmed hypertension

$B M I$ Body mass index, CHOL Cholesterol, CKD Chronic Kidney Disease, COPD Chronic Obstructive Pulmonary Disease, DBP Diastolic Blood Pressure, EBG Elevated Blood Glucose, FPG, Fasting Plasma Glucose, HDL High-density Lipoprotein, HUA Hyperuricemia, LDL Low-density Lipoprotein, NVAF Nonvalvular Atrial Fibrillation, TG Triglycerides, SBP, Systolic Blood Pressure 
hyperthyroidism, or COPD between the two groups (Table 1).

\section{Prevalence of EBG among Guangzhou residents}

Prevalence of EBG among Guangzhou residents was $29.9 \%$ overall and increased with age in the overall population and similarly in the sex subgroups (Fig. 1). In each age group younger than the 60-64 age group, men had a higher prevalence of EBG than women. The prevalence of EBG was similar for the sex subgroups after age 6064 age; however, in the 70-74 age range, men had numerically higher EBG than women. There were interaction effects between age-60-year-old and sex in the prevalence of EBG $(F=4.183, P=0.041)$. Using 60 as age cutoff, we included age as a categorical variable into the subsequent statistical analyses.

\section{Association between EBG and NVAF in the overall study population}

As shown in Table 2, individuals with history of hypertension, T2D, hyperthyroidism, or COPD were associated with NVAF significantly. History of T2D had a significantly association with NVAF $(\mathrm{OR}=2.33,95 \% \mathrm{CI}$ : 1.53-3.56, $P<0.001)$, even after adjusting for age (OR = 1.29, 95\% CI: $1.05-1.60, P=0.018$ ).

There were a total of 3440 individuals with EBG, including and 1412 with T2D. The association between EBG and NVAF was examined by multivariable logistic regression analysis (Table 3 ). EBG was significantly associated with NVAF $(\mathrm{OR}=1.94,95 \% \mathrm{CI}: 1.40-2.70, P<$
0.000 ; and the age-adjusted $\mathrm{OR}=1.44$, 95\% CI: $1.03-$ 2.02, $P=0.032)$. The association between EBG and prevalence of NVAF remained statistically significant after separately adjusting for waist circumference, BP, HDL, or TG (all $P<0.05$ ). In multivariable-adjusted models, EBG remained a significant association with NVAF $(\mathrm{OR}=1.60,95 \% \mathrm{CI}: 1.14-2.25, P=0.007)$. Thus, EBG was associated with NVAF independently from other metabolic abnormalities in the overall population.

The OR for NVAF among individuals with T2D was 2.34 (95\% CI: $1.55-3.54, P<0.001$ ), and that this association was attenuated to 1.65 after adjustment for age. Multivariable adjustment for metabolic factors had little effect on this association estimate (OR: 2.29, 95\% CI: $1.51-3.48, P<0.001)$.

IFG was significantly associated with NVAF (OR = 1.67, 95\% CI: $1.11-2.51, P=0.014)$. Statistical significance of the association was lost after adjustment for age (OR $=1.29,95 \% \mathrm{CI}: 0.85-1.95, P=0.231$ ) or for other metabolic abnormalities $(\mathrm{OR}=1.41,95 \% \mathrm{CI}=0.93-2.14$, $P=0.104)$.

\section{Sex difference in the association between EBG and NVAF in the Guangzhou community}

The associations between EBG and NVAF in sex subgroups were examined by multivariable logistic regression analysis (Table 3). EBG was not significantly associated with NVAF among men in neither unadjusted model $(\mathrm{OR}=1.57,95 \%$ CI: $0.98-2.53, \quad P=0.062)$ nor multivariable-adjusted models (all $P>0.05$ ). Men with

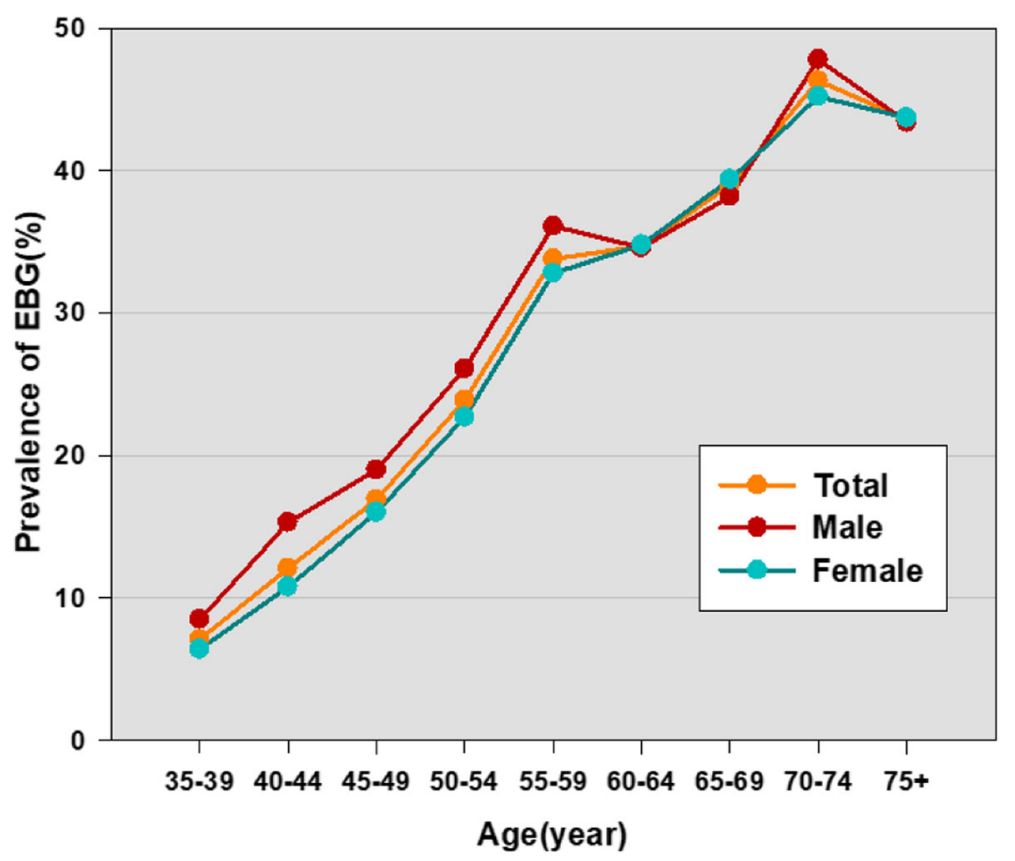

Fig. 1 Age-specific prevalence of EBG in the study population. EBG: Elevated Blood Glucose 
Table 2 Risk Factors for NVAF from Medical History

\begin{tabular}{|c|c|c|c|c|}
\hline \multirow[t]{2}{*}{ Risk Factors } & \multicolumn{2}{|c|}{ Univariable model } & \multicolumn{2}{|c|}{ Age-adjusted model } \\
\hline & OR $(95 \% \mathrm{Cl})$ & $P$-value & OR $(95 \% \mathrm{Cl})$ & $P$-value \\
\hline Hypertension history & $3.52(2.52-4.92)$ & $<0.001$ & $2.21(1.56-3.14)$ & $<0.001$ \\
\hline T2D history & $2.33(1.53-3.56)$ & $<0.001$ & $1.29(1.05-1.60)$ & 0.018 \\
\hline Hyperthyroidism & $2.20(1.26-3.85)$ & 0.009 & $2.18(1.24-3.82)$ & 0.007 \\
\hline COPD & $2.80(1.73-4.52)$ & $<0.001$ & $2.20(1.36-3.57)$ & 0.001 \\
\hline Smoking & $1.36(0.94-1.98)$ & 0.100 & $1.23(0.85-1.79)$ & 0.273 \\
\hline Alcohol Consumption & $0.66(0.42-1.04)$ & 0.085 & $0.74(0.47-1.17)$ & 0.202 \\
\hline Tea Consumption & $1.03(0.71-1.50)$ & 0.919 & $1.11(0.77-1.62)$ & 0.575 \\
\hline Urban & $1.19(0.86-1.66)$ & 0.292 & $1.10(0.79-1.53)$ & 0.576 \\
\hline
\end{tabular}

Cl Confidence Interval, COPD Chronic Obstructive Pulmonary Disease, NVAF Non-valvular Atrial Fibrillation, OR Odds ratio, T2D Type 2 Diabetes Mellitus

T2D had a 2.29-fold greater prevalance of NVAF (95\%CI: $1.30-4.01, \quad P=0.004)$, and the association decreased slightly but remained statistically significant after adjustment for age and other metabolism abnormal factors (all $P<0.05)$. There were no statistically significant differences between men with or without IFG (OR $=0.93,95 \% \mathrm{CI}$ : $0.48-1.80, P=0.834$ ), while for women, the OR for those with EBG was 2.29 (95\% CI: 1.44-3.64, $P=0.001$ ), and for those with T2D was 2.25 (95\% CI: $1.22-4.18, P=0.010$ ). However, after adjusting for age and combined metabolic disease separately or as a whole, the significant association for women with EBG remained (overall OR $=1.80$, 95\% CI: 1.12-2.91, $P=0.016$ ), while that for women with T2D did not (overall OR $=1.71,95 \% \mathrm{CI}$ : $0.90-3.23, P=0.099$ ). IFG was significantly associated with NVAF among women $(\mathrm{OR}=2.32,95 \% \mathrm{CI}: 1.36-3.96, P=0.002)$, even after adjustment for age $(\mathrm{OR}=1.78,95 \% \mathrm{CI}: 1.03-3.06$, $P=0.038)$ or multivariable adjustment $(\mathrm{OR}=1.86,95 \% \mathrm{CI}$ : 1.08-3.22, $P=0.026)$. There were no interaction effects between sex and EBG in the prevalence of $\operatorname{NVAF}(F=$ $0.030, P=0.863$ ).

\section{Discussion}

\section{Main findings of the study}

The present study documented that: 1. EBG (T2D and IFG) was not rare among adults in Guangzhou, China, with $29.9 \%$ prevalence $(31.9 \%$ for men, and $28.9 \%$ for women); 2. Presence of EBG was associated with a significantly higher (1.9-fold, and 1.6-fold or 1.4-fold after adjustment for combined metabolic comorbidities or age) prevalence of NVAF than that among individuals with normal glucose metabolism; and 3. EBG was significantly associated with NVAF presence in the overall population, and in women, mainly those with IFG.

\section{Association between abnormal glucose metabolism and prevalence of NVAF}

Diabetes mellitus, a strong, independent risk factor for $\mathrm{AF}$, is one of the most rapidly growing chronic illnesses in the world [1, 2, 22-25]. The twofold increased prevalence of NVAF among individuals with EBG in this study is consistent with the 1.8-fold risk increase reported in previous studies on the southwestern [26] and northern [7] populations of China. Increased association persisted after adjustment for metabolic confounders.

EBG includes T2D and IFG. In a previous meta-analysis, individuals with T2D were at significantly increased risk for new-onset AF (summary relative risk $=1.34,95 \% \mathrm{CI}$ : 1.07-1.68) [8]. In our study, T2D was significantly associated with NVAF $(\mathrm{OR}=2.34)$ even after adjustment for other metabolic diseases. IFG, as a pre-diabetes condition, is common worldwide and usually not treated with hypoglycemic agents. IFG has been associated with a significantly increased risk of new-onset AF (hazard ratio = 1.16) $[9,27]$, and in our study, IFG was significantly associated with the prevalance for abnormal glucose metabolism related NVAF among women.

\section{Effect of sex on the relationship between EBG and prevalence of NVAF}

The present study documented a higher prevalence of NVAF among men, which is consistent with previous studies $[6,7,15]$, and in contrast to a previous Chinese cohort study in which men did not have increased risk of AF [26]. Previous studies on the southwestern [26] and northern [7] populations of China demonstrated a significant association between diabetes mellitus and AF, but neither mentioned the effect of sex. In the present study, the independent association of EBG and NVAF as well as the predictive value of EBG for NVAF was not apparent among men, which was consistent with previous findings [28].

Multivariable-adjusted models in the present study suggested that IFG was associated with NVAF among women, although female sex was not a risk factor for cardiovascular disease in contrast to male. Therefore, this study would suggest that patients need to be alert about their glycemic status, particularly at the pre-diabetes stage. 
Table 3 Risk of NVAF According to the Presence or Absence of Abnormal Glucose Metabolism

\begin{tabular}{|c|c|c|c|c|}
\hline \multicolumn{5}{|c|}{ Models for the overall population } \\
\hline \multirow{2}{*}{$\begin{array}{l}\text { Characteristics } \\
(N=11,488)\end{array}$} & \multicolumn{4}{|c|}{ Glucose Metabolism } \\
\hline & Normal & EBG & T2D & IFG \\
\hline $\begin{array}{l}\text { No. of NVAF/No. of } \\
\text { participants }\end{array}$ & $79 / 8048$ & $65 / 3440$ & $32 / 1412$ & $33 / 2028$ \\
\hline $\begin{array}{l}\text { Univariable-adjusted } \\
\text { model }\end{array}$ & Referent & $\begin{array}{l}1.94 \\
(1.40- \\
2.70) \\
0.000\end{array}$ & $\begin{array}{l}2.34 \\
(1.55- \\
3.54) \\
0.000\end{array}$ & $\begin{array}{l}1.67 \\
(1.11- \\
2.51) \\
0.014\end{array}$ \\
\hline Age-adjusted model & Referent & $\begin{array}{l}1.44 \\
(1.03- \\
2.02) \\
0.032\end{array}$ & $\begin{array}{l}1.65 \\
(1.08- \\
2.51) \\
0.019\end{array}$ & $\begin{array}{l}1.29 \\
(0.85- \\
1.95) \\
0.231\end{array}$ \\
\hline $\begin{array}{l}\text { Waist circumference- } \\
\text { adjusted model }\end{array}$ & Referent & $\begin{array}{l}1.71 \\
(1.22- \\
2.39) \\
0.002\end{array}$ & $\begin{array}{l}2.00 \\
(1.32- \\
3.05) \\
0.001\end{array}$ & $\begin{array}{l}1.50 \\
(1.00- \\
2.27) \\
0.053\end{array}$ \\
\hline BP-adjusted model & Referent & $\begin{array}{l}1.65 \\
(1.18- \\
2.31) \\
0.004\end{array}$ & $\begin{array}{l}1.94 \\
(1.27- \\
2.96) \\
0.002\end{array}$ & $\begin{array}{l}1.44 \\
(0.95- \\
2.18) \\
0.084\end{array}$ \\
\hline TG-adjusted model & Referent & $\begin{array}{l}2.04 \\
(1.46- \\
2.85) \\
0.000\end{array}$ & $\begin{array}{l}2.50 \\
(1.64- \\
3.80) \\
0.000\end{array}$ & $\begin{array}{l}1.74 \\
(1.15- \\
2.62) \\
0.009\end{array}$ \\
\hline HDL-adjusted model & Referent & $\begin{array}{l}1.92 \\
(1.37- \\
2.67) \\
0.000\end{array}$ & $\begin{array}{l}2.29 \\
(1.51- \\
3.48) \\
0.000\end{array}$ & $\begin{array}{l}1.66 \\
(1.10- \\
2.49) \\
0.016\end{array}$ \\
\hline $\begin{array}{l}\text { Waist circumference/BP/ } \\
\text { TG/HDL-adjusted model }\end{array}$ & Referent & $\begin{array}{l}1.60 \\
(1.14- \\
2.25) \\
0.007\end{array}$ & $\begin{array}{l}1.87 \\
(1.22- \\
2.87) \\
0.004\end{array}$ & $\begin{array}{l}1.41 \\
(0.93- \\
2.14) \\
0.104\end{array}$ \\
\hline
\end{tabular}

Models for the male population

\begin{tabular}{|c|c|c|c|c|}
\hline Characteristics & \multicolumn{4}{|c|}{ Glucose Metabolism } \\
\hline$(N=4047)$ & Normal & EBG & $\mathrm{T} 2 \mathrm{D}$ & IFG \\
\hline $\begin{array}{l}\text { No. of NVAF/No. of } \\
\text { participants }\end{array}$ & $41 / 2754$ & $30 / 1293$ & $14 / 873$ & $12 / 754$ \\
\hline $\begin{array}{l}\text { Univariable-adjusted } \\
\text { model }\end{array}$ & Referent & $\begin{array}{l}1.57 \\
(0.98- \\
2.53) \\
0.062\end{array}$ & $\begin{array}{l}2.29 \\
(1.30- \\
4.01) \\
0.004\end{array}$ & $\begin{array}{l}0.93 \\
(0.48- \\
1.80) \\
0.834\end{array}$ \\
\hline Age-adjusted model & Referent & $\begin{array}{l}1.26 \\
(0.78- \\
2.04) \\
0.350\end{array}$ & $\begin{array}{l}1.87 \\
(1.06- \\
3.30) \\
0.030\end{array}$ & $\begin{array}{l}0.84 \\
(0.44- \\
1.62) \\
0.604\end{array}$ \\
\hline $\begin{array}{l}\text { Waist circumference- } \\
\text { adjusted model BP- } \\
\text { adjusted model }\end{array}$ & Referent & $\begin{array}{l}1.32 \\
(0.82- \\
2.15) \\
0.256\end{array}$ & $\begin{array}{l}1.86 \\
(1.05- \\
3.29) \\
0.034\end{array}$ & $\begin{array}{l}0.93 \\
(0.49- \\
1.79) \\
0.834\end{array}$ \\
\hline TG-adjusted model & Referent & $\begin{array}{l}1.49 \\
(0.92- \\
2.41) \\
0.109\end{array}$ & $\begin{array}{l}2.15 \\
(1.21- \\
3.81) \\
0.009\end{array}$ & $\begin{array}{l}1.02 \\
(0.53- \\
1.96) \\
0.950\end{array}$ \\
\hline HDL-adjusted model & Referent & $\begin{array}{l}1.62 \\
(1.00- \\
2.61) \\
0.048\end{array}$ & $\begin{array}{l}2.37 \\
(1.35- \\
4.18) \\
0.003\end{array}$ & $\begin{array}{l}1.10 \\
(0.57- \\
2.10) \\
0.779\end{array}$ \\
\hline
\end{tabular}

Table 3 Risk of NVAF According to the Presence or Absence of Abnormal Glucose Metabolism (Continued)

\begin{tabular}{lllll}
\hline \multicolumn{4}{c}{ Models for the overall population } \\
\hline Characteristics & \multicolumn{4}{c}{ Glucose Metabolism } \\
\cline { 2 - 5 }$(\mathrm{N}=11,488)$ & Normal & EBG & T2D & IFG \\
\hline Waist circumference/BP/ & Referent & 1.56 & 2.27 & 1.07 \\
TG/ & $(0.97-$ & $(1.29-$ & $(0.56-$ \\
& $2.52)$ & $4.00)$ & $2.04)$ \\
& 0.066 & 0.004 & 0.842 \\
HDL- adjusted model & Referent & 1.33 & 1.88 & 0.93 \\
& & $(0.81-$ & $(1.05-$ & $(0.48-$ \\
& $2.17)$ & $3.35)$ & $1.80)$ \\
& 0.258 & 0.034 & 0.834
\end{tabular}

Models for the female population

\begin{tabular}{|c|c|c|c|c|}
\hline \multirow{2}{*}{$\begin{array}{l}\text { Characteristics } \\
\qquad(N=7441)\end{array}$} & \multicolumn{4}{|c|}{ Glucose Metabolism } \\
\hline & Normal & EBG & $\mathrm{T} 2 \mathrm{D}$ & IFG \\
\hline $\begin{array}{l}\text { No. of NVAF/No. of } \\
\text { participants }\end{array}$ & $38 / 5294$ & $35 / 2147$ & $14 / 873$ & $21 / 1274$ \\
\hline $\begin{array}{l}\text { Univariable-adjusted } \\
\text { model }\end{array}$ & Referent & $\begin{array}{l}2.29 \\
(1.44- \\
3.64) \\
0.001\end{array}$ & $\begin{array}{l}2.25 \\
(1.22- \\
4.18) \\
0.010\end{array}$ & $\begin{array}{l}2.32 \\
(1.36- \\
3.96) \\
0.002\end{array}$ \\
\hline Age-adjusted model & Referent & $\begin{array}{l}1.63 \\
(1.02- \\
2.61) \\
0.041\end{array}$ & $\begin{array}{l}1.45 \\
(0.78- \\
2.71) \\
0.245\end{array}$ & $\begin{array}{l}1.78 \\
(1.03- \\
3.06) \\
0.038\end{array}$ \\
\hline $\begin{array}{l}\text { Waist circumference- } \\
\text { adjusted model BP- } \\
\text { adjusted model }\end{array}$ & Referent & $\begin{array}{l}1.97 \\
(1.23- \\
3.16) \\
0.005\end{array}$ & $\begin{array}{l}1.88 \\
(1.01- \\
3.51) \\
0.048\end{array}$ & $\begin{array}{l}2.04 \\
(1.19- \\
3.51) \\
0.010\end{array}$ \\
\hline TG-adjusted model & Referent & $\begin{array}{l}1.78 \\
(1.11- \\
2.85) \\
0.017\end{array}$ & $\begin{array}{l}1.69 \\
(0.90- \\
3.16) \\
0.101\end{array}$ & $\begin{array}{l}1.85 \\
(1.07- \\
3.18) \\
0.027\end{array}$ \\
\hline HDL-adjusted model & Referent & $\begin{array}{l}2.47 \\
(1.54- \\
3.95) \\
0.000\end{array}$ & $\begin{array}{l}2.48 \\
(1.32- \\
4.66) \\
0.005\end{array}$ & $\begin{array}{l}2.45 \\
(1.43- \\
4.22) \\
0.001\end{array}$ \\
\hline $\begin{array}{l}\text { Waist circumference/BP/ } \\
\text { TG/ }\end{array}$ & Referent & $\begin{array}{l}2.27 \\
(1.43- \\
3.62) \\
0.001\end{array}$ & $\begin{array}{l}2.22 \\
(1.19- \\
4.14) \\
0.012\end{array}$ & $\begin{array}{l}2.31 \\
(1.35- \\
3.95) \\
0.002\end{array}$ \\
\hline HDL- adjusted model & Referent & $\begin{array}{l}1.80 \\
(1.12- \\
2.91) \\
0.016\end{array}$ & $\begin{array}{l}1.71 \\
(0.90- \\
3.23) \\
0.099\end{array}$ & $\begin{array}{l}1.86 \\
(1.08- \\
3.22) \\
0.026\end{array}$ \\
\hline
\end{tabular}

ORs, $95 \% \mathrm{Cls}, P$-values were expressed in the model lines of the chart above. $B P$ Blood Pressure, EBG Elevated Blood Glucose, HDL High-density Lipoprotein, NVAF Non-valvular Atrial Fibrillation, TG Triglycerides, T2D Type 2

Diabetes Mellitus

\section{Limitations}

The present study has limitations inherent to its crosssectional design with a relatively small regional sample size which precluded assessment of statistical significance for some age subgroups. Although we tried by various means to capture all evidence to diagnose $\mathrm{AF}$, including AF history, electrocardiogram on the spot, and single-lead $24 \mathrm{~h}$ ECG monitor, the AF prevalence might 
have been underestimated. Underdiagnosis of abnormal glucose metabolism also might have occurred due to long transport time that might have blood glugose levels been underestimated, and the lack of OGTT and undiagnosed IGT and DM based on postprandial glucose levels. Larger, multiregional, randomized controlled studies with long-term follow-up are warranted to further assess the relationship between abnormal glucose metabolism and the prevalence of new-onset AF.

\section{Conclusions}

In this large report from the Guangzhou Heart Study, adults aged 35 and older in Guangzhou, China with EBG had a significantly higher prevalence of NVAF independently of metabolic comorbidities. The significant association between EBG and NVAF was apparent among women but not men. IFG was associated with prevalence of NVAF among women.

\section{Abbreviations}

AF: Atrial fibrillation; AUC: Area under the receiver operating characteristic curve; BP: Blood pressure; CHOL: Cholesterol; Cl: Confidence interval; CKD: Chronic kidney disease; COPD: Chronic obstructive pulmonary disease: DBP: Diastolic blood pressure; EBG: Elevated blood glucose level;

ECG: Evaluations including electrocardiography; FPG: Fasting plasma glucose; HDL: High-density lipoprotein; HUA: Hyperuricemia; IFG: Impaired fasting glucose; LDL: Low-density lipoprotein cholesterol; NVAF: Non-valvular atrial fibrillation; OR: Odds ratio; ROC: Receiver operating characteristic; SBP: Systolic blood pressure; SD: Standard deviation; T2D: Type 2 diabetes mellitus

\section{Acknowledgements}

The authors thank all the residents involved in the study for the cooperation.

\section{Authors' contributions}

$L F, H D, Y-m X, W-d L, F-Z L, Y L X-z Z, X-h F, H-t L, Z-I L$ and S-IW conceived the study, analysed data, interpreted and drafted the manuscript. S-fH, L-hT, Z-yF, $\mathrm{M}-\mathrm{rZ}$ and WW collected data and completed the survey. All authors have read and approved the manuscript.

\section{Funding}

The study was partially supported by the Standardized Clinical Research and Popularization of Atrial Fibrillation Catheter Ablation Techniques (No. 2014Y2-00196), the Optimization of Prevention and Treatment Strategies for Stroke in Atrial Fibrillation and Establishment of the Prevention Network (No. 201508020261), and the National Natural Science Foundation (No. 81870254). The Standardized Clinical Research and Popularization of Atrial Fibrillation Catheter Ablation Techniques (No. 2014Y2-00196) and the Optimization of Prevention and Treatment Strategies for Stroke in Atrial Fibrillation and Establishment of the Prevention Network (No. 201508020261) mainly helped with the design of the study and collection of data. And the National Natural Science Foundation (No. 81870254) helped with analysis, and interpretation of data and in drafting the manuscript.

\section{Availability of data and materials}

The data are available from the corresponding author on reasonable request.

\section{Ethics approval and consent to participate}

This study was approved by the Guangzhou Medical Ethics Committee of the Chinese Medical Association (No. GDREC2015306H) and was conducted in accordance with the ethical standards of the 1964 Helsinki Declaration and its later amendments or comparable ethical standards. All participants provided written informed consent.

\section{Consent for publication}

Not applicable.

\section{Competing interests}

The authors declare that they have no competing interests.

\section{Author details}

'Department of Cardiology, Guangdong Provincial People's Hospital, Guangdong Academy of Medical Sciences, Guangdong Cardiovascular Institute, Guangzhou 510080, China. ${ }^{2}$ Guangdong Provincial Key Laboratory of Clinical Pharmacology, Research Center of Medical Sciences, Guangdong Academy of Medical Sciences, Guangzhou 510080, China. ${ }^{3}$ Guangzhou Center for Disease Control and Prevention, Guangzhou 510440, China.

Received: 16 February 2019 Accepted: 11 November 2019

Published online: 28 November 2019

\section{References}

1. Kannel WB, Abbott RD, Savage DD. Epidemiologic features of chronic atrial fibrillation: the Framingham study. N Engl J Med. 1982;306:1018-22.

2. Stewart S, Hart CL, Hole DJ. A population-based study of the long-term risks associated with atrial fibrillation: 20-year follow-up of the Renfrew/Paisley study. Am J Med. 2002;113:359-64.

3. Chugh SS, Havmoeller R, Narayanan K, et al. Worldwide epidemiology of atrial fibrillation: a global burden of disease 2010 study. Circulation. 2014; 129:837-47

4. Benjamin EJ, Levy D, Vaziri SM, et al. Independent risk factors for atrial fibrillation in a population-based cohort. Framingham Heart Study JAMA. 1994:271:840-4.

5. Korantzopoulos P. Obesity and the risk of new-onset atrial fibrillation. JAMA. 2005;293:1974 author reply 1975.

6. Schnabel RB, Sullivan LM, Levy D, et al. Development of a risk score for atrial fibrillation (Framingham heart study): a community-based cohort study. Lancet. 2009:373:739-45.

7. Li Y, Pastori D, Guo Y, et al. Risk factors for new-onset atrial fibrillation: a focus on Asian populations. Int J Cardiol. 2018;261:92-8.

8. Huxley RR, Filion KB, Konety S. Meta-analysis of cohort and case-control studies of type 2 diabetes mellitus and risk of atrial fibrillation. Am J Cardiol. 2011;108:56-62.

9. Lee SS, Ae Kong K, Kim D, et al. Clinical implication of an impaired fasting glucose and prehypertension related to new onset atrial fibrillation in a healthy Asian population without underlying disease: a nationwide cohort study in Korea. Eur Heart J. 2017;38:2599-607.

10. Gu D, Reynolds $K, W u X$, et al. Prevalence of the metabolic syndrome and overweight among adults in China. Lancet. 2005;365:1398-405.

11. Conen D, Ridker PM, Mora S, et al. Blood pressure and risk of developing type 2 diabetes mellitus: the Women's health study. Eur Heart J. 2007;28: 2937-43.

12. UK Prospective Diabetes Study (UKPDS) Group. Effect of intensive bloodglucose control with metformin on complications in overweight patients with type 2 diabetes (UKPDS 34). Lancet. 1998:352:854-65.

13. Niskanen L, Laaksonen DE, Nyyssönen $K$, et al. Inflammation, abdominal obesity, and smoking as predictors of hypertension. Hypertension. 2004;44: 859-65.

14. Leslie WS, Hankey CR, Lean MEJ. Weight gain as an adverse effect of some commonly prescribed drugs: a systematic review. Q J Med. 2007; 100:395-404.

15. Deng $\mathrm{H}$, Guo P, Zheng M, et al. Epidemiological characteristics of atrial fibrillation in southern China: results from the Guangzhou heart study. Sci Rep. 2018:8:17829.

16. Zhou Z. An epidemiological study on the prevalence of atrial fibrillation in the Chinese population of mainland China. J Epidemiol. 2008;18:209-16.

17. Gallagher MM. Classification of atrial fibrillation. Am J Cardiol. 1998;82: $18 \mathrm{~N}-28 \mathrm{~N}$

18. January CT, Wann LS, Alpert JS, et al. 2014 AHA/ACC/HRS guideline for the management of patients with atrial fibrillation: executive summary: a report of the American College of Cardiology/American Heart Association task force on practice guidelines and the Heart Rhythm Society. Circulation. 2014;130:2071-104

19. American Diabetes Association. Diagnosis and classification of diabetes mellitus. Diab Care. 2005;28(Suppl 1):S37-42.

20. Alberti KG, Eckel RH, Grundy SM, et al. Harmonizing the metabolic syndrome: a joint interim statement of the international diabetes federation task force on epidemiology and prevention; National Heart, Lung, and 
Blood Institute; American Heart Association; world heart federation; international atherosclerosis society; and International Association for the Study of obesity. Circulation. 2009;120:1640-5.

21. Levey $A S$, Stevens $L A$, Schmid $C H$, et al. A new equation to estimate glomerular filtration rate. Ann Intern Med. 2009;150:604-12.

22. Miyasaka $Y$, Barnes ME, Gersh BJ, et al. Secular trends in incidence of atrial fibrillation in Olmsted County, Minnesota, 1980 to 2000, and implications on the projections for future prevalence. Circulation. 2006;1 14:119-25.

23. Lloyd-Jones DM, Wang TJ, Leip EP, et al. Lifetime risk for development of atrial fibrillation: the Framingham heart study. Circulation. 2004;1 10:1042-6.

24. Gami AS, Hodge DO, Herges RM, et al. Obstructive sleep apnea, obesity, and the risk of incident atrial fibrillation. J Am Coll Cardiol. 2007;49:565-71.

25. Movahed MR, Hashemzadeh M, Jamal MM. Diabetes mellitus is a strong, independent risk for atrial fibrillation and flutter in addition to other cardiovascular disease. Int J Cardiol. 2005:105:315-8.

26. Guo Y, Tian Y, Wang H, Si Q, Wang Y, Lip GYH. Prevalence, incidence, and lifetime risk of atrial fibrillation in China: new insights into the global burden of atrial fibrillation. Chest. 2015;147:109-19.

27. Latini R, Staszewsky L, Sun JL, Bethel MA, Disertori M, Haffner SM, Holman RR, Chang F, Giles TD, Maggioni AP, Rutten GE, Standl E, Thomas L, Tognon $G$, Califf RM, McMurray JJ. Incidence of atrial fibrillation in a population with impaired glucose tolerance: the contribution of glucose metabolism and other risk factors. A post hoc analysis of the Nateglinide and Valsartan in Impaired Glucose Tolerance Outcomes Research trial. Am Heart J. 2013;166: 935-40 e931.

28. Schoen T, Pradhan AD, Albert CM. Type 2 diabetes mellitus and risk of incident atrial fibrillation in women. J Am Coll Cardiol. 2012;60:1421-8.

\section{Publisher's Note}

Springer Nature remains neutral with regard to jurisdictional claims in published maps and institutional affiliations.

Ready to submit your research? Choose BMC and benefit from:

- fast, convenient online submission

- thorough peer review by experienced researchers in your field

- rapid publication on acceptance

- support for research data, including large and complex data types

- gold Open Access which fosters wider collaboration and increased citations

- maximum visibility for your research: over $100 \mathrm{M}$ website views per year

At BMC, research is always in progress.

Learn more biomedcentral.com/submissions 